\title{
Supportive and motivating environments in school: Main factors to make well-being and learning a reality
}

\author{
Anne G. Danielsen \\ Faculty of Education, Bergen University College, 5020 Bergen \\ Korrespondanse: anne.danielsen@psyph.uib.no
}

\begin{abstract}
The author examined the relationships between (i) school-related social support from parents, teachers, and classmates, respectively, and students' perceived life satisfaction; and (ii) school-related social support from teachers and classmates and self-reported academic initiative. The analyses were based on data from nationally representative samples of 13- and 15-year-old students from the Norwegian part of the sixth and seventh World Health Organization (WHO) international survey of Health Behavior in School-aged Children (HBSC). The Structural Equation Modeling (SEM) analyzing approach was employed. The findings indicate that school-related social support is positively related to students' perceived life satisfaction and self-reported academic initiative. In two-level SEM analysis, a latent factor comprising pedagogical caring and autonomy support was substantially related to self-reported academic initiative at the class level.
\end{abstract}

\section{INTRODUCTION}

The positive psychological constructs of subjective life satisfaction and self-determination are frequently referred to in empirically based psychology research on positive development in children and youth. Positive psychology stress that efforts to improve children's lives must focus on developing strengths, facilitating positive responses to adversity, and strengthening the important institutions in children's lives. The main purpose of the present paper was to apply a positive psychological perspective in identifying supportive and motivating factors in the school environment that may relate to positive developmental outcomes in terms of academic initiative and life satisfaction of students.

There are three pillars of positive psychology: (a) positive subjective experiences, like subjective wellbeing (SWB) and life satisfaction; (b) positive personality - a perspective on human beings as selforganizing, self-directed, self-regulated, adaptive entities, which is focused in e.g. self-determination theory (Ryan \& Deci, 2000), and (c) positive institutions e.g. schools, bringing out the best in positive character and subjective experiences - recognizing that people and experiences are embedded in social contexts (Seligman \& Csikszentmihalyi, 2000).

Subjective well-being (SWB) is about quality of life or "happiness" and refers to people's own evaluations of their lives, both affective and cognitive (Diener, 2000; Diener et al., 2003). The project studied a separable component of SWB; perceived life satisfaction, as for school students in Norway. Perceived life satisfaction is an important cognitive aspect of SWB (Huebner et al., 2005), and refers to global, cognitive judgments of one's life (Pavot et el., 1991). In addition, self-reported academic initiative was examined, which is considered an expression of autonomous, self-regulated learning (cf. Reeve et al., 2008). Self- regulated learning can comprise motivational variables (such as self-efficacy and task interest) and other selfprocesses (such as personal goal-setting and the use of learning strategies) (Zimmerman \& Cleary 2006; Boekarts, 1997). Self-regulated learners are often described as autonomous learners who set goals for themselves and use meta-cognition (such as planning, monitoring, and evaluation) to reach their goals (Boekarts, 1997; Woolfolk, 2004).

Self-determination theory (SDT) focuses on three innate psychological needs (relatedness, competence, autonomy) as sources of autonomous self-regulated motivation. To the extent the school environment allows students to experience satisfaction of these needs, the students' self-regulated motivation will be optimal. The notion of autonomous self-regulated motivation or self-determined motivation - concerns active engagement in tasks people find interesting or important and will promote growth (Reeve et al., 2008). Selfdetermined motivation would most likely stimulate and develop students' academic initiative, enabling the students to fulfil their individual potentials and capacities and enhance their life satisfaction.

\section{Previous research}

\section{Life satisfaction}

Most young adolescents report relatively high levels of life satisfaction, according to a study which included 11-, 13- and 15-year-old school-students in 41 countries and regions across Europe and North America (Currie et al., 2008). According to conceptual work by Huebner et al. (1998), school may be one of the life domains with the largest impact on students' life satisfaction. There is evidence that social support from family, teachers, and peers is associated with perceived life satisfaction (Diener \& Fujita, 1995). Relatively few studies have however been conducted of adolescents' overall life satisfaction (Huebner et al., 2005). 
Academic initiative

To the knowledge of the author, academic initiative, as defined and operationalized in the project, was not previously examined. The development of youth initiative has however been studies in different social contexts, especially in structured voluntary activities (for a literature review, see Danielsen, 2010). Unlike structured voluntary activities, school is usually not a context typically conducive for the development of youth initiative according to Larson, because, during schoolwork, students report low intrinsic motivation (Larson, 2000).

\section{School environment}

Findings from previous Norwegian studies indicate that compared to other countries, there are relatively minor differences between schools in the country (The Education Mirror, 2006). Moreover, variance is greater "between school classes at each school" (The Education Mirror, 2006, p. 18) in Norway. The school class is therefore a relevant unit of analysis of processes that occur within the classroom, such as associations between students' perceptions of teacher behaviors and their academic initiative.

At the school class level, previous findings have suggested strong relationships between teacher emphatic involvement and student perceived motivational climate (Stornes et al., 2008). Moreover, positive correlations have been found between different achievement goal structures, such as perceptions of an emphasis on mastery goals versus performance goals in the classroom, and a student's personal motivation (for a review, see Urdan \& Schoenfelder, 2006). Students in the same class can further differ in their perceptions of the learning environment, as they may be affected by their own personal characteristics (Bru et al., 2002).

\section{Research questions}

The paper addressed the following main research questions:

1. To what extent is perceived school-related social support, provided by parents, teachers, and classmates, related to students' perceived life satisfaction?

2. To what extent do perceived social- and autonomysupport provided by teachers, and perceived social support provided by classmates, relate to students' self-reported academic initiative at the individual and at the school class levels?

3. To what extent is students' perceived life satisfaction and self-reported academic initiative related?

\section{METHOD}

\section{Health Behavior in School-aged Children (HBSC)}

This study is based on two papers (First: Danielsen et al., 2009; second: Danielsen et al., 2010) of the author's PhD thesis (Danielsen, 2010). The first paper used Norwegian survey data from nationally representative samples of 13- and 15-year-olds, collected for the sixth World Health Organization (WHO) survey of
Health Behavior in School-aged Children (HBSC) (Currie et al., 2004). The second paper was based on Norwegian survey data from a nationally representative sample of 13-year-olds, collected for the seventh HBSC-study (Currie et al., 2008). HBSC is an international research project, and from 1983 and onwards, the HBSC study has been conducted every fourth year on school-aged children in the age groups 11-, 13- and 15-year-olds. The main aim of the sixth survey was to provide new insights into predictors of young people's health, well-being, and health behavior (Currie et al., 2004). For the seventh survey, the main aim was to highlight where health inequalities exist, to inform and influence policy and practice, and to help improve health for all young people (Currie et al., 2008). National reports of the two Norwegian surveys are available (Torsheim et al., 2004; Samdal et al., 2009).

\section{Samples}

For the analyses of the first paper, we used a sample of 13-year-olds ( $\mathrm{N}=1736,49 \%$ girls $)$ and 15-year-olds ( $\mathrm{N}=1622,51 \%$ girls) from the $2001 / 02$ Norwegian survey in the HBSC study. The response rate in the first paper was $78 \%$ (Torsheim et al., 2004). Data from a HBSC 2005/06 sample of Norwegian 13-year-olds ( $n=1591,48 \%$ girls) were used in the second paper. In the second paper, the response rate was 59\% (Samdal et al., 2009).

The data were collected in December 2001 and December 2005. The students were selected using a geographically stratified, systematic sampling procedure (Currie et al, 2004; Currie et al., 2008), and thus yielding a nationally representative sample (Samdal et al., 2009). The sampling unit was the school class. Within the participating classes (grade 8; grade 10), all students belonging to the participating school classes were invited to participate.

In Norway, 13-year-olds attend the first year, and 15-year-olds the final year, of the compulsory lower secondary school, attendance at which lasts for three years (grades 8-10). Each student is attached to a teacher ("contact teacher") with specific responsibility for the practical, administrative and social educational tasks concerning the student, including contact with the home (Norwegian Education Act, 1998).

\section{Ethical considerations}

National ethical approval was obtained from the Regional Committee for Medical Research Ethics (REK). The students were informed that their participation was voluntary, and they were assured of the anonymity of their responses. Informed consent was obtained from principals, while passive consent was obtained from the parents, who were offered the opportunity to decline participation.

\section{Students' life satisfaction}

We employed Huebner's Students' Life Satisfaction Scale (SLSS) (Huebner, 1991), which is a measure of global life satisfaction specifically designed to assess 
life satisfaction in children and adolescents (Huebner et al., 2004). The SLSS is a measure of students' internal, reflective appraisals of reality, and the SLSS takes a broad view of the life satisfaction concept and requires respondents to make overall life assessments, not related to specific domains or areas (Huebner et al., 2004). The study used the nine-item scale version of the SLSS. This global, one-dimensional measure of students' perceived life satisfaction contained statements like: "I have a good life/I feel good about what's happening". To respond, students selected one of four response keys: never, sometimes, often, and almost always, to indicate how often experienced life satisfaction during the past few weeks. Cronbach's alpha was .88.

\section{Academic initiative}

Students' self-reported academic initiative was assessed using five items, for example: "I challenge myself when I am doing schoolwork" and "I set goals for myself when I am doing schoolwork". The four response categories were (1) "never", (2) "sometimes", (3) "often", and (4) "almost always". The items were adopted from the Youth Experience Survey (YES 2.0), developed in the USA by Hansen et al. (2003) and Hansen and Larson (2005) to measure initiative and other self-reported experiences in the context of organized youth activities. Cronbach's alpha was .84 .

\section{School-related support}

Four constructs were used to measure support in the school environment; parental support, teacher support, classmate support, and student autonomy (Danielsen, 2010).

\section{Parental support}

Four items indicated parental support, for example "My parents are interested in what happens to me at school". Cronbach's alpha was .85 .

\section{Teacher support}

In the first paper (Danielsen et al., 2009), a five-item scale of teacher support was used, for example "Our teachers treat us fairly". Cronbach's alpha was .82. For reasons of space, the number of items was cut down in the second paper (Danielsen et al., 2010), and the teacher support scale then consisted of two items. Cronbach's alpha for the items was .80 .

\section{Classmate support}

The perceived classmate support scale consisted of four items in the first paper, for example "Most of the student in my class(es) are kind and helpful". Cronbach's alpha was .75. In the second paper, the perceived classmate support scale consisted of three items. Cronbach's alpha was .84 .

\section{Student autonomy}

The following two items were used to measure perceived student autonomy: "students have a say in their use of class time" and "students have a say in activities". Cronbach's alpha was .85.

\section{Data collection}

Teachers, or other specially trained personnel, supervised the students' self-completion of the questionnaires in the school classrooms. Each student was allowed 45 minutes to complete the survey. Completed questionnaires were placed into envelopes and sealed by the student before being handed in.

\section{Statistical analyses}

Descriptive analysis such as reliability testing, productmoment correlations, and independent samples $t$-test were conducted using SPSS (SPSS Inc., n.d.). Mplus version 5.1 (Muthén \& Muthén, 1998-2007) was used to run the other analyses.

\section{Structural equation modeling}

The structural equation modeling (SEM) analyzing approach was used to answer the second research question. We judged the goodness of model fit according to cut-off criteria recommended by $\mathrm{Hu} \&$ Bentler (1999) and Marsh et al. (2004). As chi-square is highly sensitive to sample size, the global model fit was estimated by a comparative fit index (CFI); a root mean square error of approximation (RMSEA); and a standardized root mean squared residual (SRMR). CFI assesses the relative improvement in the fit of the hypothesized model compared with a baseline model that assumes unrelated variables (Kline, 2005). Values of CFI greater than .95 may indicate reasonable goodness of fit of the hypothesized model. RMSEA is a "badness of fit" index in that the best fit is indicated by a value of zero, and higher values indicate a worse fit (Kline). A rule of thumb is that RMSEA equal to or below .05 indicates close approximate fit. In addition, values of SRMR close to .08 may indicate reasonable goodness of fit of the hypothesized model at the class level.

Missing data were handled by using the full information maximum likelihood (FIML) procedure which has been regarded a state of the art as long as missing data is missing at random (Schafer \& Graham, 2002).

\section{Multilevel modeling}

Regarding the second research question, two-level structural equation modeling (SEM) was undertaken. By the use of two-level modeling, the relationships between the predictor variables and the outcome academic initiative were examined both at the student level and the school class level. Intraclass correlations (ICC) and design effects (cf. Snijders \& Bosker, 1999) of items were estimated to determine variation in the variables across school classes. For the analysis, an estimator referred to as MLR (robust maximum likelihood) was applied. This is a non-normality robust technique.

\section{Generalizability}

The sample sizes were large, and the procedures for drawing the samples were developed to ensure that the samples were nationally representative. Thus, the results can be generalized to the Norwegian populations that were studied (Samdal et al., 2009). 


\section{RESULTS}

\section{Descriptive statistics}

\section{Paper I}

In order to determine whether there were significant age or gender differences in the mean levels of the study variables that were used in paper I (Danielsen et al., 2009), we conducted independent samples $t$-tests for equality of means. At both ages, boys (age 13=27.90; age $15=26.46$ ) reported higher levels of life satisfaction than girls (age $13=27.11$; age $15=24.81$ ). There were no statistically significant gender differences in perceived support, except perceived classmate support, which was higher among girls than boys at age 13 . The means for all scales were significantly lower among 15 -year-olds than 13-year-olds in both genders. Table 1 presents the correlation values for the study variables of the first paper of the thesis (Danielsen et al., 2009). The relationships between students' perceived life satisfaction and the predictor variables were positive and substantial. All of these correlations were significant $(p<0.01)$.

\section{Paper II}

Table 2 presents descriptive statistics of the study variables of the second paper of the thesis (Danielsen et al., 2010).

The design effects for the indicators of self-reported academic initiative ranged from 1.69 to 2.54 . Using a design effect of more than two as a rule of thumb (cf. Hox, 2002), the design effects for both indicators of perceived teacher support (3.44 and 2.99) were considered to be large. The design effects of the items that measured classmate support and student autonomy were less than two (Danielsen et al., 2010).

Self-reported academic initiative varied across classes with a difference (unexplained class-level variance) of $12 \%$, according to analysis of the null model (i.e., when no exogenous were included in the model). The standardized path coefficients from the two-level

Table 1. Bivariate correlations among the scales (paper I).

\begin{tabular}{lccc}
\hline Subscales paper I & 1 & 2 & 3 \\
\hline 1. Teacher support & - & & \\
2. Classmate support & $.36^{*}$ & - & \\
3. Parental support & $.32 *$ & $.26^{*}$ & - \\
4. Life satisfaction & $.31^{*}$ & $.32^{*}$ & $.32^{*}$ \\
\hline${ }^{*}<0.01$ & & &
\end{tabular}

Table 2. Descriptive statistics and bivariate correlations between the study variables (paper II).

\begin{tabular}{lccccc}
\hline & & \multicolumn{5}{c}{ Bivariate correlations } \\
\cline { 3 - 6 } Subscales paper II & M & SD & 1 & 2 & 3 \\
\hline 1. Academic initiative & 2.64 & .72 & - & & \\
2. Teacher support & 3.95 & .94 & $.28^{*}$ & & \\
3. Classmate support & 4.25 & .67 & $.24^{*}$ & $.26^{*}$ & \\
4. Student autonomy & 3.00 & 1.05 & $.16^{*}$ & $.28^{*}$ & $.19^{*}$ \\
\hline$* p<.01$ & & & & &
\end{tabular}

SEM analysis indicated that, at the individual student level, perceived teacher support (.20) and classmate support $(.20)$ were significantly related to student selfreported academic initiative $(\mathrm{p}<.001)$. The influence of perceived student autonomy was not significant at the individual level. A strong correlation $(r=.75)$ was observed between perceived teacher support and perceived student autonomy at the class level $(\mathrm{p}<.001)$. A latent second-order factor of these variables, "Pedagogical caring and autonomy support" (PCAS) was then constructed and examined. Theoretically, this makes sense as it is primarily the teacher who provides both pedagogical caring and opportunities for student autonomy in a class. Regression paths between PCAS and academic initiative and between classmate support and academic initiative were included at the class level. PCAS was strongly related to academic initiative at the class level with a path coefficient of $.86(p<$ $.001)$. Classmate support did not relate significantly to academic initiative at the class level. The model explained $88 \%$ of the variance in self-reported academic initiative that occurred across classes. The goodnessof-fit for the model was CFI $=.984$; RMSEA $=.027$, SRMR at the individual level $=.023$; and SRMR at the class level .087, which are considered acceptable (see Hu \& Bentler, 1999; Marsh et al., 2004).

The bivariate correlations (Pearson's r) between academic initiative and students' perceived life satisfaction was .20 $(\mathrm{p}<.01)$ (Danielsen, 2010). This suggests a positive and modest relationship between the two outcomes of the study.

\section{DISCUSSION}

The overall purpose of the paper was to apply a positive psychological perspective in identifying schoolrelated factors that relate to positive development in terms of academic initiative and life satisfaction in adolescence.

\section{School-related support and students' perceived life satisfaction}

The study examined how school-related social support provided by parents, teachers, and classmates was associated with students' perceived life satisfaction. The findings indicated that these relationships were quite substantial, which support that positive subjective experiences in schools (Seligman \& Csikszentmihalyi, 2000) are important to life satisfaction in adolescence. The findings of Danielsen et al. (2009) further revealed that the relationship between parental support and students' perceived life satisfaction, and the relationship between classmate support and students' perceived life satisfaction, may also be associated with experiences in other life domains than school. Those findings suggested that multiple life domains may be involved in regard to school-related social support provided by parents and classmates, which seems reasonable because these two groups of support providers are likely to also interact with the students in the home 
environment and in leisure time activities. One might speculate that there may be interrelated mechanisms of social inclusion/exclusion for example, that work across domains of school, home, and leisure time activities, which may cause change in (and improve/worsen) students' perceived life satisfaction (cf. Bronfenbrenner, 1979).

\section{School-related support and students' self-reported academic initiative}

The findings also suggest that teachers play a key role in promoting student initiative in the school context. The students' perceptions of pedagogical caring and autonomy support (PCAS) from their teachers were strongly related (.86) to self-reported academic initiative at the class level. Based on large design effects, the study further revealed that students' perceptions of teacher support varied considerably between school classes. In line with those of previous studies (Bru et al., 2002; Stornes et al., 2008; Urdan \& Schoenfelder, 2006), the results suggested that 13-year-old students share perceptions about the psychosocial characteristics of their learning environment. The findings may indicate that some school classes provide more favourable environments for the development of academic initiative than do others, and that teachers may provide the basis for a supportive climate for the class.

The main processes involved in students' self-reported academic initiative seem however to operate at the individual student level. Because of the interpersonal character of relatedness, such as a sense of being close to students (Ryan \& Deci, 2000) and pedagogical caring (Wenzel, 1997), the processes examined in the study are likely to operate between individuals. Within a school class, different students may perceive the relationships differently, as mentioned in the introduction (cf. Bru et al., 2002; Urdan \& Schoenfelder, 2006). Perceived teacher and classmate support were moderately related to academic initiative at the student level.

Because the study primarily concerned schoolrelated social support for relatedness (Danielsen et al., 2009), the findings furthermore support the existence of a relational zone (Goldstein, 1999) and emphasize the importance of pedagogical caring (Wentzel, 1997), relatedness, and emotional support (Malecki \& Demaray, 2003) in the learning environment. Social relationships and support can be seen as crucial to human life, both to nurture a global need to belong and to provide more situational or task specific support (cf.
Baumeister \& Leary, 1995). Students tend to report low and decreasing intrinsic motivation in the school context (Larson, 2000; Lepper et al., 2005). Ryan and Deci (2000) find that the primary reason why people perform activities that are not typically interesting is because such activities are stimulated, modeled or valued by significant others to whom they feel (or want to feel) attached or related. Because relatedness is likely to facilitate internalization of the value of schoolwork, relatedness may facilitate students' engagement with school and have a positive influence on students' initiative for those school tasks that initially are not intrinsically motivated. The findings support the emphasis on an inclusive school environment, which is central in the national curriculum in Norway (Knowledge Promotion, 2006).

\section{Limitations}

Caution is appropriate regarding the interpretation of the results. Because the cross-sectional design of the study only allowed evaluation of relationships between variables at one point in time, causal relationships between the variables could not be determined. The structural model of paper II (Danielsen et al., 2010) represents a simplified approximation of reality, and it could be argued that there is a complexity with respect to the relationships between the study variables, which was not represented in the model.

\section{Conclusions}

The findings support the notion that active encouragement in the school environment is related to selfreported academic initiative and perceived life satisfaction in adolescence.

\section{Implications}

By supporting students' experiences of relatedness, competence, and autonomy in the school environment, a developmental pathway to psychological well-being and autonomous self-regulated learning may open. In the perspective of SDT (Ryan \& Deci, 2000) interpersonal involvement, competence-involving structure, and autonomy support are crucial and mutually supportive factors in this regard. It may be important to further examine developmental and motivational processes during the years at lower secondary school to obtain a more thorough understanding of the processes involved in students' self-reported academic initiative and perceived life satisfaction.

\section{REFERENCES}

Baumeister RF, Leary MR (1995). The need to belong: Desire for interpersonal attachments as a fundamental human motivation. Psychol Bull, 117, 497.

Boekarts M (1997). Self-regulated learning: A new concept embraced by researchers, policy makers, educators, teachers, and students. Learning and Instruction, 7, 161-186.

Bronfenbrenner U (1979). The ecology of human development: Experiments by nature and design. Cambridge, MA: Harvard University Press. 
Bru E, Stephens P, Torsheim T (2002). Students' perceptions of class management and reports of their own misbehavior. J School Psychol, 40, 287-307.

Currie C, et al. (Eds.) (2004). Young people's health in context: Health behaviour in school-aged children (HBSC) study: International report from the 2001/2002 study. Copenhagen World Health Organization.

Currie C, et al. (Eds.) (2008). Inequalities in young people's health: International report from the HBSC 2005/06 survey. WHO Policy Series: Health policy for children and adolescents Issue 5. Denmark: WHO Regional Office for Europe.

Danielsen AG (2010). Perceived psychosocial support, students' self-reported academic initiative and perceived life satisfaction. Thesis for the degree of Ph.d, University of Bergen.

Danielsen AG, Samdal O, Hetland J, Wold B (2009). School-related social support and students' perceived life satisfaction. J Educ Res, 102, 303-318.

Danielsen AG, Wiium N, Wilhelmsen B, Wold, B (2010). Perceived support provided by teachers and classmates and students' self-reported academic initiative. J School Psychol, 48 (3), 247-267.

Diener E (2000). Subjective well-being the science of happiness and a proposal for a national index. Am Psychologist, 55, 34-43.

Diener E, Fujita F (1995). Resources, personal strivings, and subjective well-being: A nomothetic and idiographic approach. J Pers Soc Psychol, 68 (5), 926-935.

Diener E, Oishi S, Lucas RE (2003). Personality, culture, and subjective well-being: Emotional and cognitive evaluations of life. Annu Rev Psychol, 54, 403-425.

Goldstein L (1999). The relational zone: The role of caring relationships in the co-construction of mind. Am Educ Res $J$, 36, 647-673.

Hansen DM, Larson R, Dworkin J (2003). What adolescents learn in organized youth activities: A survey of selfreported developmental experiences. J Res Adolesc, 13, 25-56.

Hansen DM, Larson R (2005). The Youth Experience Survey 2.0: Instrument revisions and validity testing. Urbana-Champaign: University of Illinois.

Hox J (2002). Multilevel analysis techniques and applications. London: Lawrence Erlbaum Associates.

Hu L-T, Bentler PM (1999). Cutoff criteria for fit indexes in covariance structure analysis: Conventional criteria versus new alternatives. Structural Equation Modeling, 6, 1-55.

Huebner ES (1991). Initial development of the Student's Life Satisfaction Scale. School Psychol Int, 12 (3), 231.

Huebner ES, Laughlin JE, Ash C, Gilman R (1998). Further validation of the Multidimensional Students' Life Satisfaction Scale. J Psychoeduc Assess, 16 (2), 118.

Huebner ES, Suldo SM, Smith LC, McKnight CG (2004). Life satisfaction in children and youth: Empirical foundations and implications for school psychologists. Psychology in the Schools, 41 (1), 81.

Huebner ES, Valois RF, Paxton RJ, Drane JW (2005). Middle school students' perceptions of quality of life. $J$ Happiness Stud, 6 (1), 15.

Kline RB (2005). Principles and practice of Structural Equation Modeling. New York, The Guilford Press.

Knowledge Promotion (2006). Ministry of Education and Research, Norway. Retrieved June, 2, 2009 from: http:/www.regjeringen.no/en/dep/kd/Selected-topics/compulsory-education/Knowledge-Promotion/Newelements-in-the-subject-syllabuses.html?id=86772.

Larson RW (2000). Toward a psychology of positive youth development. Am Psychologist, 55, 170-183.

Lepper MR, Corpus JH, Iyengar SS (2005). Intrinsic and extrinsic motivational orientations in the classroom: Age differences and academic correlates. J Educ Psychol, 97, 184-196.

Malecki CK, Demaray MK (2003). What type of support do they need? Investigating student adjustment as related to emotional, informational, appraisal, and instrumental support. School Psychol Q, 18, 231-252.

Marsh HW, Hau K-T, Wen Z (2004). In search of golden rules: Comment on hypothesis-testing approaches to setting cutoff values for fit indexes and dangers in overgeneralizing $\mathrm{Hu}$ and Bentler's (1999) findings. Structural Equation Modeling, 11, 320-341.

Muthén LK, Muthén BO (1998-2007). Mplus user's guide (5th edn). Los Angeles, CA: Muthén \& Muthén.

Norwegian Education Act (1998). Government, Norway. Retrieved February 12, 2009, from http://www. regjeringen.no/upload/KD/Vedlegg/Grunnskole/EducationActNorway19December2008.pdf

Pavot WW, Diener EE, Colvin CCR, Sandvik EE (1991). Further validation of the Satisfaction with Life Scale: Evidence for the cross-method convergence of well-being measures. J Personality Assess, 57 (1), 149.

Reeve J, Ryan R, Deci EL, Jang H (2008). Understanding and promoting autonomous self-regulation: A selfdetermination theory perspective. In: Schunk DH, Zimmerman BJ (Eds.), Motivation and self-regulated learning (pp. 223-244). New York: Lawrence Erlbaum Associates.

Ryan RM, Deci EL (2000). Self-determination theory and the facilitation of intrinsic motivation, social development, and well-being. Am Psychologist, 55, 68-78.

Samdal O, Leversen I, Torsheim T, Manger MS, Brunborg GS, Wold B (2009). HEMIL-rapport 3. Trender i helse og livsstil blant barn og unge 1985-2005. Hentet 4. august 2010, fra: https://www.uib.no/filearchive/hevas- 
rapport-2009-samdal-et-al 5.pdf.

Schafer JL, Graham JW (2002). Missing data: Our view of the state of the art. Psychol Meth, 7 (2), 147-177.

Seligman MEP, Csikszentmihalyi M (2000). Positive psychology: an introduction. Am Psychologist, 55, 5-14.

Snijders T, Bosker R (1999). Multilevel Analysis. An introduction to basic and advanced multilevel modeling. London: Sage Publications.

SPSS Inc (n.d.). Retrieved November 28, 2008, from www.spss.com.

Stornes T, Bru E, Idsoe T (2008). Classroom social structure and motivational climates: On the influence of teachers' involvement, teachers' autonomy support and regulation in relation to motivational climates in school classrooms. Scand J Educ Res, 52, 315-329.

The Education Mirror (2006). Norwegian Directorate for Education and Training, Norway. Retrieved September 10, 2007, from http://www.udir.no/upload/Forskning/the education mirror 2006.pdf.

Torsheim T, Samdal O, Wold B, Hetland J (2004). Helse og trivsel blant barn og unge: Norske resultater fra studien "Helsevaner blant skoleelever: en WHO-studie i flere land". [Health and well-being among children and youth: Norwegian results from the study "Health behaviour in school-aged children: A WHO crossnational study"; in Norwegian]. Bergen: Universitetet i Bergen, HEMIL-senteret.

Urdan T, Schoenfelder E (2006). Classroom effects on student motivation: Goal structures, social relationships, and competence beliefs. J School Psychol, 44, 331-349.

Wentzel KR (1997). Student motivation in middle school: The role of perceived pedagogical caring. $J$ Educ Psychol, 89, 411-419.

Woolfolk, A. (2004). Educational psychology (9th edn.). Boston, MA: Allyn \& Bacon.

Zimmerman BJ, Cleary T (2006). Development of personal agency: The role of self-efficacy beliefs and selfregulatory skill. In: Urdan T, Pajares F (Eds.), Self-Efficacy Beliefs of Adolescents, 45-69. Greenwich, CT: Information Age Publishing. 